\title{
Overall Motivation and the Promotion of EFL Learners' Oral Proficiency
}

\author{
Arman Toni \\ Islamic Azad University, Science and Research Branch, Tehran, Iran \\ Email: armantoni@hotmail.com \\ Mohsen Rostami (corresponding author) \\ Malmö University, Malmö, Sweden
}

\begin{abstract}
Over the past few decades, there has been an increasing concern for examining the human personality to find answers to language learning problems. As a result, good numbers of studies have focused on the crucial role that affective variables can play in the process of learning a second language. Among these variables, motivational factors are frequently recognized as potentially influential in successful L2 learning, especially in contexts or countries where there is no or little chance for learners to be in contact with the target language native speakers. Therefore, a consequent question is whether or not and to what extent motivation plays any role in developing learners' speaking proficiency in such particular contexts. More specifically, the present study investigates the degree of correlation between motivation and speaking proficiency in the Iranian EFL context. The result of the investigation conducted with Iranian lower intermediate English learners revealed that speaking abilities and motivation are positively and significantly correlated.
\end{abstract}

Index Terms — affective factors, motivation, attitude, L2 proficiency

\section{INTRODUCTION}

The history of motivation studies in second language learning goes back to Gardner and Lambert (1972) welldistinguished research program. They note that motivation to learn a second language is grounded in positive attitudes toward the second language community and in a desire to communicate with valued members of that community and become similar to them. Gardner is also responsible for the development of a battery of motivation testing instrument known as the Attitudinal/Motivational test battery; AMTB (Gardner, 1985). This model has stimulated a large number of empirical studies and has resulted in attempts to synthesize the findings of such studies into a model which is called the socio-educational model (Gardner, 1988, 2001).

In the socio-educational model, motivation to learn the second language is viewed as a driving force which requires three elements: effort, desire and enthusiasm. First, the motivated individual expends effort to learn the language. That is, there is a persistent and consistent attempt to learn the material by doing homework, by seeking out opportunities to learn more, by doing extra work, etc. Second, the motivated individual wants to achieve the goal. Such an individual will express the desire to succeed, and will strive to achieve success. Third, the motivated individual will enjoy the task of learning the language (Gardner, 2001). In this model, the elements of effort, desire and positive affect or enthusiasm are also key clues to distinguish more motivated individuals from less motivated ones. Each element, by itself, is seen as insufficient to reflect motivation. Some students may display effort, even though they have no strong desire to succeed, and may not find the experience particularly enjoyable. Others may want to learn the language, but may have other things which detract them from their effort. "The point is that the truly motivated individual displays effort, desire and affect" (Gardner, 2001). According to socio-educational model of second language acquisition, achievement in second language acquisition is an attribute of the following associated set of measures of individual differences.

Integrativeness: Favorable attitudes toward the target group, interest in foreign languages,

Attitudes toward the Learning Situation: affective reactions to any aspect of the class, the materials, the curriculum, the teacher, etc,

Motivation: Motivational intensity, desire to learn the Language, attitudes toward learning the language,

Language Anxiety: Language class anxiety and language use anxiety which can have deleterious effects on learning, Instrumentality: Instrumental orientation; where the language is being studied for practical or utilitarian purposes.

In the Attitude/Motivation Test Battery, integrativeness represents group-focused affective reactions. It reflects openness to other cultures in general, and an interest in the target culture in particular. Individuals who are high in integrativeness do not focus on their own ethno-linguistic community as a major part of their identity, but instead are willing and able to take on features of another language group as part of their own behavioral repertoire. Attitudes toward the learning situations refer to affective reactions to any aspect of the class and could be assessed in terms of the atmosphere in the class, the quality and the availability of materials, the curriculum, the teacher, etc. 
Motivation, according to Gardner, is a multifaceted concept of which fundamentals are best identified by three measures that assess effort and persistence, the desire to learn the language, and affective reactions to learning the language. Language anxiety refers to the feeling of anxiety and concern in using the language in the classroom and other contexts and is believed to result from previous experiences in language classes and/or deficiencies in language knowledge and skill. The notion of instrumentality refers to conditions where the language is studied for practical or utilitarian purposes. Like integrativeness, there could be many causes for such feelings varying from the cultural setting to idiosyncratic experiences of the individual.

\section{CONCEPTUAL FRAMEWORK AND RELATED LITERATURE}

In Attitude/Motivation Test Battery, Gardner (2001) elaborates on integrative and instrumental motivation. Integrative motivation is hypothesized to be a complex of attitudinal, goal-directed, and motivational attributes. The integratively motivated individual is one who is motivated to learn the second language, has a desire or willingness to identify with the other language community, and tends to evaluate the learning situation positively. Instrumental motivation is generally characterized by the desire to obtain something practical or concrete from the study of a second language (Hudson, 2000). With instrumental motivation, the purpose of language acquisition is more utilitarian, such as meeting the requirements for school or university graduation, applying for a job, reading technical materials or achieving higher social status. Instrumental motivation is often a characteristic of foreign language learning or second language acquisition, where little or no social integration of the learner into the target language community occurs. One area where instrumental motivation can prove to be successful is in the situations like Iran where the learner is provided with no direct opportunity to use the target language and therefore, no or rare chance to interact with members of the target group.

A note to the literature of motivation studies confirms the crucial role of the instrumental motivation. Lukmani (1972) found that an instrumental orientation was more important than an integrative orientation in non-Westernized female learners of L2 English in Bombay. Svanes (1987) also noted that European and American students were considered integratively motivated to learn Norwegian in a university in Norway, whereas the Middle Eastern, African and Asian students were considered instrumentally motivated. Thus, Svanes came to the conclusion that the type of motivation is related to the background of the students. Ellis (1997) confirms that in some of the early research conducted by Gardner and Lambert, integrative motivation was viewed as being of more importance in a formal learning environment than instrumental motivation. Nevertheless, she claims that at present the importance of instrumental motivation is also stressed.

Brown (2000) points out that integrative and instrumental motivation are not necessarily mutually exclusive. To him, Learners rarely select one form of motivation when learning a second language, but rather a combination of both orientations. He cites the example of international students residing in the United States, learning English for academic purposes while at the same time wishing to become integrated with the people and culture of the country. Similarly, Belmechri and Hummel (1998) maintain that integrative and instrumental orientations are not two opposite ends in a continuum. Rather they are positively related and both are affectively-loaded goals which can sustain learning. They both may in return be enhanced by better proficiency and higher achievement in the target language (Oxford \& Shearin, 1994; Dörnyei, 1994, 2001). Gardner and MacIntyre (1991) also claim that both types of motivation contribute to linguistic proficiency. Gardner (2005b) asserts that there is no reason to expect integrativeness and instrumentality to be independent of one another. Working with the teaching of French in primary school, Burstall (1975) found that in spite of a close link between pupils' attitude and achievement, motivational characteristics of individual pupil appeared to be neither exclusively integrative nor instrumental.

From the aforementioned ideas, it can be concluded that L2 learning does not necessitate choosing either integrative or instrumental motivation, which means that both types are important. "A learner might learn an L2 well with an integrative motivation or with an instrumental one, or indeed with both" (Cook, 1991). It deserves notice that all researches do not seem to support a similar role for motivational factors. Lyczak, Fu and Ho (1976) did not find any significant correlation between achievement and motivational variables. Likewise, in a study conducted by (AbdelHafez, 1994) in Jordan, no significant correlation between the students' attitudes and motivation and their levels of achievement in the English courses was found. Moreover contrary to a good number of scholars who think that both integrative and instrumental motivation are essential elements of success, Taylor, Meynard and Rheault (1977) and Crookes and Schmidt (1991) assert that it is the integrative motivation which sustains long-term success in learning a second language.

From another stand point, achieving English language proficiency in general and oral proficiency in particular is an unquestionable goal for ELT programs in non-native circumstances. Therefore, with reference to the background presented so far, the probable relationship between motivation and oral proficiency in Iran still worth further study. As a result the present research is a new attempt for the identification of the extent of relationship between motivation and oral proficiency among Iranian English majors.

\section{STATEMENT OF THE PROBLEM}


English is taught as a foreign or an international language in Iran where there is no or little chance for the learners to be in contact with the target language native speakers. Therefore, a consequent question is whether motivation still plays any significant role in developing learners' speaking proficiency in this particular context. More specifically, the present study seeks an answer to the following question.

Is there any relationship between the Iranian EFL/EIL learners' level of motivation and their speaking performance in English?

\section{METHODOLOGY}

\section{A. Participants}

The research was conducted with 59 freshman students of English at Delta academy of foreign languages, Tehran, Iran. The population included 34 male and 25 female Persian native speakers who were learning English at the lower intermediate level. 28 subjects were studying the course Cambridge Interchange Intro and the other 31 Cambridge Interchange 1. The students came from different academic backgrounds and had already received English language instruction at least for six years right from the second year of junior high school, known as guidance school in Iran.

\section{B. The Instrument}

In order to measure the subjects' motivation level, Mihaljevic Djigunovic (1998) model was adopted. This model is designed based on Gardner's Attitudinal/Motivational Test Battery (AMTB) and includes 38 Likert-type five-point scales items, measuring different types of motivation as well as two demotivators. The first demotivator is teachingsetting demotivator which is to find out whether the learner is demotivated for learning English because s/he dislikes the method of teaching used in the course, the teaching materials were not stimulating, or because of some qualities attached to the teacher (e.g. the teacher's English was not good enough, the teacher was partial in assigning grades and the like). The second demotivator, the learning difficulties demotivator, implied that the learner did not like learning English because he found it too difficult and complicated to learn or that he lost ground and could not cope with the learning material because of deficient knowledge base.

Since the students came from different academic and socio-economic backgrounds and due to the difference in their level of proficiency in English, and to ensure their understanding of the items, the questionnaire was administered in the participants mother tongue i.e. Persian. The original English version of the questionnaire is provided in the Appendix.

\section{Procedure}

The motivation questionnaire was administered in the first week of the Spring semester, starting from April 2011. During the completion process, one researcher was present to monitor the administration or help the respondents with understanding of the items, if necessary. At the end of the semester students' scores on the speaking courses were obtained from their instructors and the data were then statistically analyzed.

\section{RESUlTS AND DisCUSSION}

Table I presents the overall motivation mean for the sample. The subjects reported an average motivation of 2.61, and 0.21 standard deviation. From the reported Standard Deviation, it is clear that the sample was relatively homogeneous and the students showed a limited range of variation in their motivation. It also deserves notice that the mean reported for the motivation of the subjects was slightly about midpoint.

TABLE I.

STUDENTS' OVERALL MOTIVATION LEVEL

\begin{tabular}{|c|c|c|}
\hline & $\mathrm{Mm}$ & $\mathrm{SDm}$ \\
\hline Overall Motivation & 2.61 & 0.21 \\
\hline \multicolumn{3}{|c|}{$\mathrm{M}_{\mathrm{m}}=$ motivations mean } \\
$\mathrm{SD}_{\mathrm{m}}=$ Standard Deviation of motivation scores
\end{tabular}

At the end of the term, students' scores on speaking assessment were collected and the same statistical operation was computed. The results represented in Table II reveal an average of 15.9 on speaking assessment of the sample. The table also shows a standard deviation of 1.34 for speaking assessment. With reference to the SD observed, it is clear that participants showed a greater variation in their speaking scores. Additionally, the mean reported for the participants speaking score in 0-20 scale indicates for a medium to high level of proficiency.

TABLE II.

STUDENTS' SPEAKING PROFIECIENCY SCORES
\begin{tabular}{|l|l|l|}
\hline & $\mathrm{Mp}$ & $\mathrm{SDp}$ \\
\hline Speaking Proficiency & 15.9 & 1.34 \\
\hline
\end{tabular} Mp=proficiency mean
SDp=proficiency Standard Deviation


To compute the degree of relationship between motivation and speaking proficiency, the Pearson product-moment correlation coefficient was computed between the two sets of variables.

TABLE III.

CORRELATION COEFFIECIENT (R) BETWEEN MOTIVAITON AND SPEAKING PROFIENCY

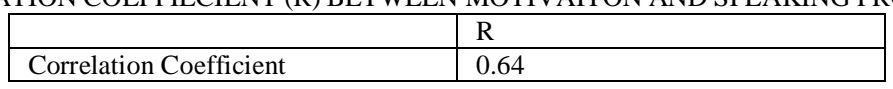

With reference to critical values for Pearson product-moment correlation coefficient, Learners motivation was found to have a significant correlation with their speaking proficiency at the level of $\mathrm{p}<.01$. However, as Brown and Rodgers (2002) indicate, such results are accurately interpreted only when all their underlying assumptions are met. A complete list of their intended assumptions is as follows.

1. Scales Assumption: both sets of numbers must be in continuous scales.

2. Independence Assumption: the pairs of numbers within a data set must be independent of one another.

3. Normality Assumption: both distributions must be normal.

4. Linearity Assumption: the two sets of numbers, if plotted on a scatter plot should be more or less in a line.

A critical note to the data gathered makes it clear that they are in continuous or interval scale, and the two sets are independent of one another, i.e. scores in either pair might not influence the generation of the other scores. Thus, the first and the second assumptions have been met. The third assumption requires a variation of at least two standard deviations from the Mean. That is, Mean $\pm 2 S D$ must be within the range of minimum and maximum scores. Further examination of the data revealed that this assumption was also met. The computations for such purpose are brought in the table that follows.

TABLE IV

COMPUTAITONS TO CHECK THE NORMALITY ASSUMPTION

\begin{tabular}{|c|c|}
\hline Set of motivation scores & $\begin{array}{l}\min _{m} \leq M_{m}-2 S D_{m} \Rightarrow 1.87 \leq 2.61-2 \times 0.21 \\
\operatorname{Max}_{m} \geq M_{m}+2 S D_{m} \Rightarrow 3.03 \geq 2.61+2 \times 0.21\end{array}$ \\
\hline Set of speaking proficiency scores & $\begin{array}{l}\min _{p} \leq M_{p}-2 S D_{p} \Rightarrow 13 \leq 15.9-2 \times 1.34 \\
\operatorname{Max}_{p} \geq M_{p}+2 S D_{p} \Rightarrow 19 \geq 15.9+2 \times 1.34\end{array}$ \\
\hline & $\begin{array}{l}\mathrm{m}=\text { motivations mean, } \\
\text { ard Deviation of motivation scores } \\
\text { ninimum score of motivation } \\
\text { naximum score of motivation } \\
\mathrm{Ip}=\text { proficiency mean, } \\
\text { rd Deviation of proficiency scores } \\
\text { mum score of proficiency scores } \\
\text { imum score of proficiency scores }\end{array}$ \\
\hline
\end{tabular}

The fourth and the last assumption is the linearity assumption. This means that unless any two sets of data are linear in relation, one cannot simply claim for their correlation. In order to have a preview of the existing correlations between the two variables, a scatter plot was drawn, the result of which is presented in Figure 1.

It can be understood from the figure that the diamonds are more or less in a straight line, and that two sets of numbers are approximately linear in relationship. Therefore the findings solidly support the correlation assumption. Thus it is right to say that the results indicate for the existence of a direct positive relationship between motivation and speaking proficiency level of Iranian EFL learners.

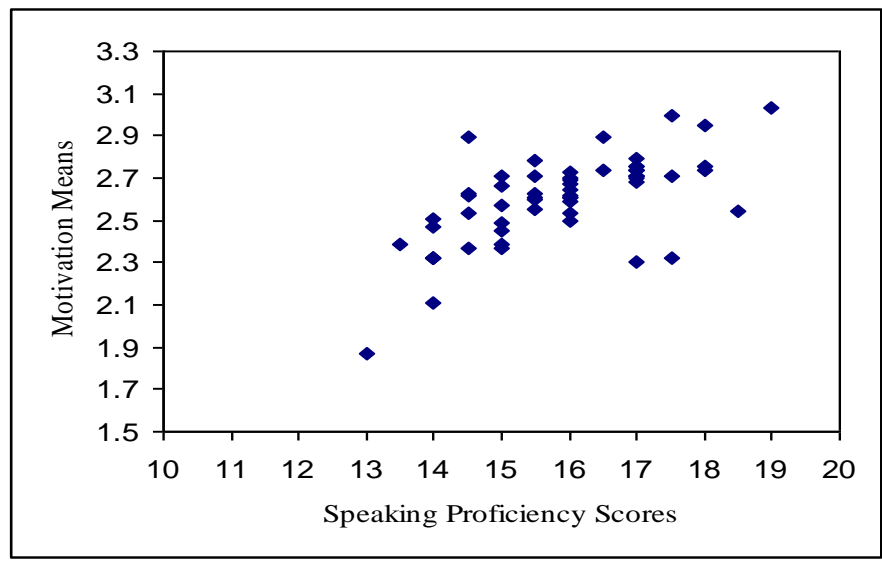

Figure 1. Scatter plot of the scores 


\section{CONCLUSION}

As it was mentioned earlier, the aim of this research project was to investigate the probable relationship existing between motivation and the speaking proficiency of English students at Delta academy of foreign languages, Tehran, Iran. The findings seem strong enough to let us claim that in EFL environment where instrumental motivation is dominantly at work, student's performance in speaking English is directly and positively correlated with their level of motivation. Therefore, the teachers are recommended to be sensitive to learners' motivation in general and their instrumental motivation in particular.

They may help students by encouraging the development of instrumental motivation. Learners' encouragement may be done through foregrounding the advantages of knowing a foreign language or elaboration on frequent uses of the language. Conducting a need analysis and estimating learner's reasons, purposes and justifications for learning English can be a different solution. Needless to say that, in so doing, teachers are expected to provide learners with more opportunities to fulfill their stated instrumental objectives.

Learners' instrumental motives can also be duly attained by helping them prepare for examination and stressing the role their English score play in their academic achievement. More focus on practical skills is also suggested for their functional and utilitarian characteristics and for the role they play in developing learners' self-esteem. Teachers may also try to raise students' integrative motivation by drawing their interest toward the target language, its literature and the culture of the people who speak it. In general, any effort to promote motivation in students and observation of learners' reactions to those efforts will be a step in the direction to find the most motivating activities for every particular class.

\section{ApPendix The Motivation Questionnaire}

1. English enables me to communicate with many people.

2. Knowing English, I can read foreign magazines.

3. English will help me in my future education.

4. I often use English to talk to foreigners.

5. English will be useful to me in my future profession.

6. English enables us to become part of the world.

7. I use English in everyday life to understand pop music, films etc.

8. Thanks to English I can broaden my cultural horizon.

9. With English I can travel all over the world.

10. Knowing English, I could read literary works in the original.

11. Sometimes I use my English to translate instructions on foreign-made machines (e.g. household appliances).

12. Thanks to English, I can learn more about the life of the English, Americans, Australians, etc.

13. English is a very interesting language.

14. English is a very beautiful language.

15. I like English words.

16. English sounds very nice.

17. I enjoy pronouncing English words.

18. English is a stupid language.

19. I would like to be like the English, Americans, Australians, etc.

20. I would like to marry someone from USA, Britain, etc.

21. I'd like to know English in order to be able to live in the USA, Britain, etc.

22. English will be useful to me when I visit my relatives/friends in the USA, Britain, Australia, etc. one day.

23. Our teacher teaches English in a very interesting way.

24. I don't like the teaching methods our teacher employs.

25. Our teacher assigns grades unjustly.

26. I'd learn English if the course was more interesting.

27. My teacher of English motivates me to learn.

28. Our teacher is not motivated to teach.

29. The teaching materials we use are very motivating.

30. I don't like learning English because I have a bad teacher.

31. Our teacher pays too much attention to good pupils.

32. During English classes I'm always in panic because I know I will not understand the teacher when she addresses me.

33. My pre-knowledge of English is so low that I could catch up with the others only if I started from the very beginning (and that I can't do, of course).

34. After getting a bad mark I have no more wish to learn.

35. English is too difficult for me.

36. My parents force me to learn English. 
37. I'd rather learn another foreign language.

38. I prefer to learn something more useful than English.

\section{REFERENCES}

[1] Abdel-Hafez, H. (1994). The influence of motivation and attitudes on the language proficiency of English majors at Yarmouk University. In M. M. Obeidat (2005). Attitudes and motivation in second language learning. Journal of Faculty of Education, 22, 1-17.

[2] Belmechri, F., \& Hummel, K. (1998). Orientations and motivation in the acquisition of English as a second language among high school students in Quebec City. Language Learning, 2, 219-244.

[3] Brown, H. D. (2000). Principles of language learning and teaching $\left(4^{\text {th }}\right.$ Ed.). Englewood Cliffs NJ: Prentice-Hall.

[4] Brown, J. D., \& Rodgers, T. S. (2002). Doing second language research. Oxford University Press.

[5] Burstall, C. (1975). Factors Effecting Foreign Language Learning: A consideration of some relevant research findings. Language Teaching and Linguistics Abstract, 8, 5-125.

[6] Cook, V. (1991). Second language learning and language teaching. London: Edward Arnold.

[7] Crookes, G., \& Schmidt, R. W. (1991). Motivation: Reporting the research agenda. Language Learning, 41, 469-512.

[8] Dörnyei, Z. (1994). Motivation and motivating in the foreign language classroom. The Modern Language Journal, 78, $273-284$

[9] Dörnyei, Z. (2001). Teaching and researching motivation. Longman: Pearson Education Limited.

[10] Ellis, R. (1997). The study of second language acquisition. Oxford: Oxford University Press.

[11] Gardner, R. C. (1985). Social psychology and second language learning: The role of attitudes and motivation. London: Edward Arnold Publishers.

[12] Gardner, R. C. (1988). The socio-educational model of second language learning: Assumptions, findings and issues. Language Learning, 38, 101-126.

[13] Gardner, R. C. (2001). Language learning motivation: The student, the teacher, and the researcher. Proceedings of the Texas Foreign Language Education Conference. University of Texas, Austin, Texas.

[14] Gardner, R. C. (2005a). The socio-educational model of second language acquisition: a research paradigm. Proceedings of Eurosla 15 Conference. Dubrovnik, Croatia.

[15] Gardner, R. C. (2005b). Integrative motivation and second language acquisition. Proceedings of the Meetings of the Canadian Association of Applied Linguistics and the Canadian Linguistics Association. The University of Western Ontario, Ontario, London, Canada.

[16] Gardner, R. C., \& Lambert, W. E. (1972). Attitudes and motivation in second language learning. Rowley, Mass.: Newbury House.

[17] Gardner, R. C., \& MacIntyre, P. D. (1991). An instrumental motivation in language study: Who says it isn't effective? Studies in Second Language Acquisition, 13, 52-72.

[18] Guiora, A. (1972). Construct Validity and Transpositional Research: Toward an Empirical Study of Psychoanalytic Concept. Comprehensive Psychiatry, 13, 139, 150.

[19] Hudson, G. (2000). Essential introductory linguistics. Malden, Mass: Blackwell Publishers.

[20] Lyczak, R., Fu, G., \& Ho, A. (1976). Attitudes of Hong Kong bilinguals towards English and Chinese speaker. Journal of Cross-Cultural Psychology, 7, 425-538.

[21] Lukmani, Y. M. (1972). Motivation to learn and language proficiency. Language Learning, 22, 261-273.

[22] Mihaljevi Djigunovi, J. (1998). Uloga afektivnih faktora u ucenju stranoga jezika. Filozofski fakultet Sveucilista u Zagrebu. In J. Mihaljevic Djigunovic (2001). Are language learning strategies motivation-specific? Language learning strategies and motivation. Orbis Linguarum, 18, 125-138.

[23] Oxford, R., \& Shearin, J. (1994). Language learning motivation: Expanding the theoretical framework. The Modern Language Journal, 78, 12-27.

[24] Svanes, B. (1987). Motivational and cultural distance in second language acquisition. Language Learning, 37, $341-359$.

[25] Taylor, D. M., Meynard, R., \& Rheault, E. (1977). Threat to ethnic identity and second-language learning. In H. Giles (Ed.), Language, ethnicity and intergroup relations (pp. 99-118). New York: Academic Press.

Arman Toni is currently a Ph.D. candidate majoring in TEFL at IAU, Science and Research Branch, Tehran, Iran. He received his M.A. in TEFL from Ilam State University and is currently a visiting instructor at IAU, Nowshahr Branch, Iran. He has published and presented papers in national and international journals and conferences. His research interests are Psycholinguistics, Sociolinguistics, and Computer Assisted Language Learning.

Mohsen Rostami is an M.A. candidate of English studies at Malmö University, Malmö, Sweden. He got his B.A. in English translation studies from IAU, Tehran Central Branch in 2004. Since then, he has been professionally involved in teaching English to EFL learners, in particular adults. As a researcher, he is concerned with observing learners' attitudes and responses toward different teaching techniques. His main research interests are psychology of language, and the implementation of translation techniques in language teaching. 